\title{
ASSESSMENT OF THE POSTERIOR APPROACH FOR SURGICAL TREATMENT OF SPINAL METASTATIC BREAST CANCER
}

\author{
AVALIAÇÃO DO TRATAMENTO CIRÚRGICO DA METÁSTASE \\ VERTEBRAL DE MAMA POR ABORDAGEM POSTERIOR
}

\author{
Mariana demétrio de Sousa Pontes ${ }^{1}$ (i), Breno de Paula Faleiros Pires ${ }^{1}$ (i), Felipe de Paula Albuquerque ${ }^{2}$ (i), \\ Carlos Fernando Pereira da Silva Herrero ${ }^{1}$ (i)
}

1. Universidade de São Paulo, Ribeirão Preto Medical School, Department of Biomechanics, Medicine and Rehabilitation of Locomotor, Ribeirão Preto, SP, Brazil.

2. Universidade de São Paulo, Ribeirão Preto Medical School, Ribeirão Preto, SP, Brazil.

\section{ABSTRACT}

Objective: To assess the clinical and radiological aspects of patients with spinal metastatic breast cancer who underwent surgical treatment by posterior approach. Methods: This is a retrospective and descriptive study. Clinical assessment included the patient's sex, age, surgical treatment employed and complications. Radiological assessment comprised the study of the morphopathological characteristics of the lesions. Results: Data from 44 patients (93.2\% female) submitted to surgical treatment of spinal metastasis were collected. The average age of diagnosis was 56.79 years. Decompression and posterior fixation with pedicle screws were performed in $43.1 \%$ of patients, while $36.3 \%$ underwent decompression and posterior fixation with pedicle screws associated with corpectomy and replacement with intersomatic device filled with bone cement. In $20.4 \%$, kyphoplasty was the chosen procedure. Eighteen percent of patients had surgical complications, and the thoracic spine was most affected by the tumor. Conclusion: The clinical and radiological presentation of this group of patients is variable. The posterior portion of the vertebrae was more affected than the anterior. Although surgical treatment by posterior approach does not have the objective of curing the underlying disease, it can present favorable results, with higher rate of complication in major surgeries. Level of evidence IV, Therapeutic Studys.

Keywords: Tumor. Spine. Arthrodesis. Breast Neoplasms.

\section{RESUMO}

Objetivo: Avaliar aspectos clínicos e radiológicos de pacientes portadores de metástase vertebral de mama, submetidos ao tratamento cirúrgico por via posterior. Métodos: Estudo retrospectivo e descritivo. A avaliação clínica incluiu o sexo, a idade, os procedimentos cirúrgicos empregados e as complicações. A avaliação radiológica envolveu o estudo das características morfopatológicas das lesões. Resultados: Foram estudados 44 pacientes submetidos ao tratamento cirúrgico das metástases vertebrais (93,2\%: feminino), com média de idade de 56,79 anos. Em 43,1\% dos pacientes foi realizada descompressão e fixação posterior com parafusos pediculares, ao passo que em 36,3\% foi feita descompressão e fixação posterior com parafusos pediculares associadas à corpectomia e substituição por dispositivo intersomático preenchido com cimento ósseo. Em 20,4\%, a cifoplastia foi o procedimento cirúrgico de escolha. Dezoito por cento dos pacientes apresentaram complicações pós-operatórias, e a coluna torácica foi a região mais acometida. Conclusão: A apresentação clínica e radiológica desse grupo de pacientes é variável. A porção posterior das vértebras foi mais acometida em relação à anterior. O tratamento cirúrgico por abordagem posterior, apesar de não possuir objetivo de cura da doença de base, pode apresentar resultados favoráveis, com taxas de complicações maiores em procedimentos mais agressivos. Nível de evidência IV, Estudos Terapêuticos.

Descritores: Tumor. Coluna Vertebral. Artrodese. Neoplasias da Mama.

Citation: Pontes MDS, Pires BPF, Albuquerque FP, Herrero CFPS. Assessment of the posterior approach for surgical treatment of spinal metastatic breast cancer. Acta Ortop Bras. [online]. 2020;28(1):22-5. Available from URL: http://www.scielo.br/aob.

\section{INTRODUCTION}

Breast cancer is the second most frequent malignant tumor in the world, being the most common among women and the leading cause of death by cancer in this population. 'I It usually grows slowly; however, depending on extrinsic and intrinsic characteristics, evolution may be more aggressive, with greater potential for dissemination. ${ }^{1}$ In these cases, the axial skeleton is the most frequent site of metastases, although pulmonary, hepatic and cerebral assailment are common. ${ }^{1}$ As a consequence, some patients with spinal metastases may develop secondary pain or neurological deficit to pathological fracture and/or direct compression of the spinal cord. ${ }^{2}$

The best treatment of spinal metastases involves the approach of several specialists. Although the therapeutic strategies used lately have been more aggressive and have shown better results, they

All authors declare no potential conflict of interest related to this article.

Study developed at the Hospital das Clínicas of Ribeirão Preto Medical School of the Universidade de São Paulo, Ribeirão Preto, SP, Brazil.

Correspondence: Mariana Demétrio de Sousa Pontes. Av. Bandeirantes, 3900, Vila Monte Alegre, Ribeirão Preto, SP, Brazil, 14049900. mdspontes@hcrp.usp.br; marianadpontes@gmail.com

Article received on 05/05/2019, approved on 06/06/2019. 
remain with the palliative purpose of reducing morbidity and improving the patients' quality of life. ${ }^{3-5}$ Surgical treatment is specifically indicated in situations such as mechanical instability, progressive tumor growth despite clinical treatment, uncontrolled pain despite medications, and significant or progressive neurological symptoms. ${ }^{4-6}$

Different surgical techniques can be chosen to treat spinal metastatic lesions, and subsequent approaches with decompression and instrumentation for stabilization and corpectomy with implant replacement are commonly carried out. ${ }^{7}$ The choice of method considers its practicality in relation to the affected column region, once not every level is equally accessible, the objectives of each procedure, and the familiarity of the surgeon with the various techniques. ${ }^{7}$

Although surgical therapy of spinal metastases has been widely adopted, the literature still lacks results according to breast cancer histopathology and the influence of negative prognostic variables, such as visceral metastases, surgical complications and advanced age at diagnosis. ${ }^{4-8}$

Accordingly, this study aims to investigate the clinical and radiological parameters of patients with breast metastasis in the spine who underwent surgical treatment by posterior approach, as well as to identify post-treatment complications.

\section{MATERIALS AND METHODS}

This is a descriptive and retrospective study of a prospective database, including 44 patients diagnosed with breast tumor metastasis in the spine, who were operated by the Orthopedics-Spinal Surgery team of the Hospital das Clínicas of the Ribeirão Preto Medical School, USP, from 2005 to 2017. The research project was approved by the Research Ethics Committee of the institution, including the exemption from the informed consent form (protocol HC 354/2018-CAAE: 82389518.0.0000.5440). The authors declare no conflict of interest regarding this article.

The inclusion criteria consisted of patients diagnosed with primary malignant breast tumor, with histopathological confirmation, submitted to posterior surgery for the treatment of spinal metastases, of both sexes, of any race, and aged over 18. Patients under the age of 18, with another primary malignant tumor, operated by an anterior or combined approach, and non-diagnosed with spinal metastasis, were excluded from the study.

Data were collected by researchers from the Medical Archiving Sector (SAME) of the hospital, and information from medical records and imaging exams were used. Clinical assessment included sex; the patient's age at the time of diagnosis; time between the secondary initial symptom to spinal metéstasis and imaging diagnosis; time between the breast tumor diagnosis; and the metastasis in the spine; neurological manifestations classif ed by the Frankel scale; ${ }^{9}$ surgical approach used; postoperative complications; and need for surgical reapproach. Radiological assessment involved the study of simple radiography, computed tomographiy and magnetic resonance exams, and the morphopathological claracteristics of the lesions were studied: level of metastasis in the spine and affected portion of the vertebra.

The parameters were stored in a spreadsheet and studied with Microsoft Excel, and the results were presented as percentages, means and medians.

\section{RESULTS}

Of the 44 patients evaluated, 41 (93.2\%) are women and 3 (6.8\%), men . Mean age at diagnosis was 56.79 , ranging from 33 to 94 years. The time between the initial symptom in the spine and the confirmation of the diagnosis of metastasis by magnetic resonance exam varied from 1 day to 3.6 years, with a mean time of 7 months, and median of 45 days. In six patients (13.6\%), the diagnosis of spinal metastasis preceded the diagnosis of primary tumor.

Forty-three percent $(n=19)$ of the individuals presented secondary neurological deficit to spinal assailment, either by fracture or by spinal cord and/or direct root compression. To classify these alterations, the Frankel scale was used in the pre and postoperative period, and we observed that $22.7 \%(n=10)$ of the patients improved their postoperative deficit, and 2.2\% $(n=1)$ worsened neurologically after the procedure. It was not possible to evaluate these data in two patients due to severe adverse events.

Regarding the surgical procedures used, all 44 patients underwent treatment by the posterior approach. In 19 (43.1\%) patients, decompression and posterior fixation with pedicular screws were performed (Figure 1), whereas 16 (36.3\%) patients underwent decompression and posterior fixation with pedicular screws associated with corpectomy and replacement with an intersomatic device filled with bone cement (Figure 2). In addition, kyphoplasty was the chosen surgical procedure in nine $(20.4 \%)$ patients.

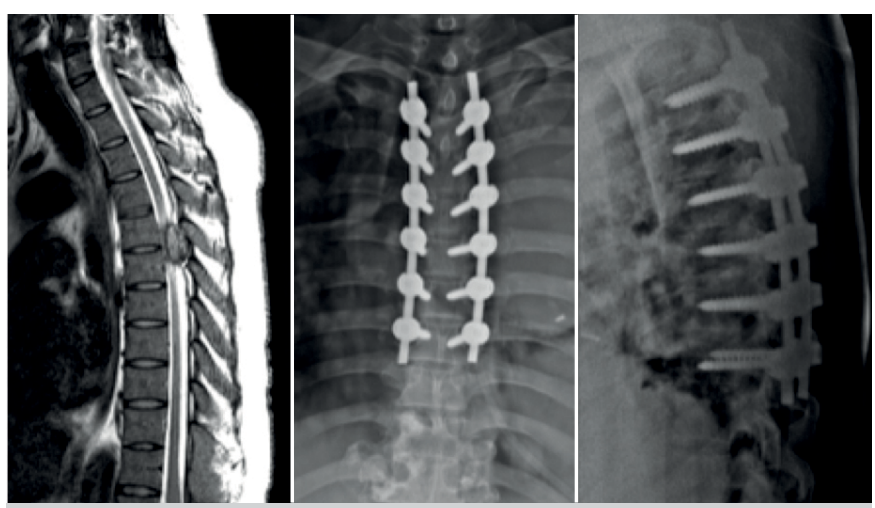

Figure 1. Sagittal cut of T2-weighted preoperative magnetic resonance evidencing image compatible with extradural metastasis by compressing the spinal cord canal at T5-T6 level. Postoperative radiographies of decompression and posterior fixation with pedicular screws.

Eight (18.1\%) patients presented postoperative complications: extradural hematoma $(4.5 \%, n=2)$, cerebrospinal fluid leak $(4.5 \%, n=2)$, infection ( $9 \%, n=4)$, surgical wound dehiscence $(2.2 \%, n=1)$, seroma formation $(2.2 \%, n=1)$, and neurological deficit $(2.2 \%, n=1)$; and six (13.6\%) patients required surgical reapproach to treat complications related to the first procedure: hematoma or seroma drainage $(6.8 \%, n=3)$; dressing in the operating room $(6.8 \%, n=3)$. Other seven $(15.9 \%)$ patients underwent a new procedure due to tumor recurrence.

Of the eight patients who presented postoperative complications, six (75\%) were submitted to decompression, corpectomy, replacement with intersomatic device and fixation with pedicular screws, while two (25\%) were subjected to decompression and fixation. Patients who chose the kyphoplasty procedure did not present complication. The spine level most affected by metastases was the thoracic, in $86.3 \%$ of the cases $(n=38)$, followed by the lumbar $(25 \%, n=11)$, cervical $(13.6 \%, n=6)$ and sacral $(9 \%, n=4)$; and the posterior portion of the vertebrae was preferably affected $(65.9 \%, n=29)$ if compared with the anterior portion (43.1\%, $n=19)$.

\section{DISCUSSION}

Although retrospective, the study adequately assessed the patients, with a thorough description of the information from the database in the Medical Archiving Service (SAME), thus offering significant conclusions. Most of the patients included in the study were women with a mean age of 56.79 at the time of diagnosis, ranging from 33 to 94 years. 

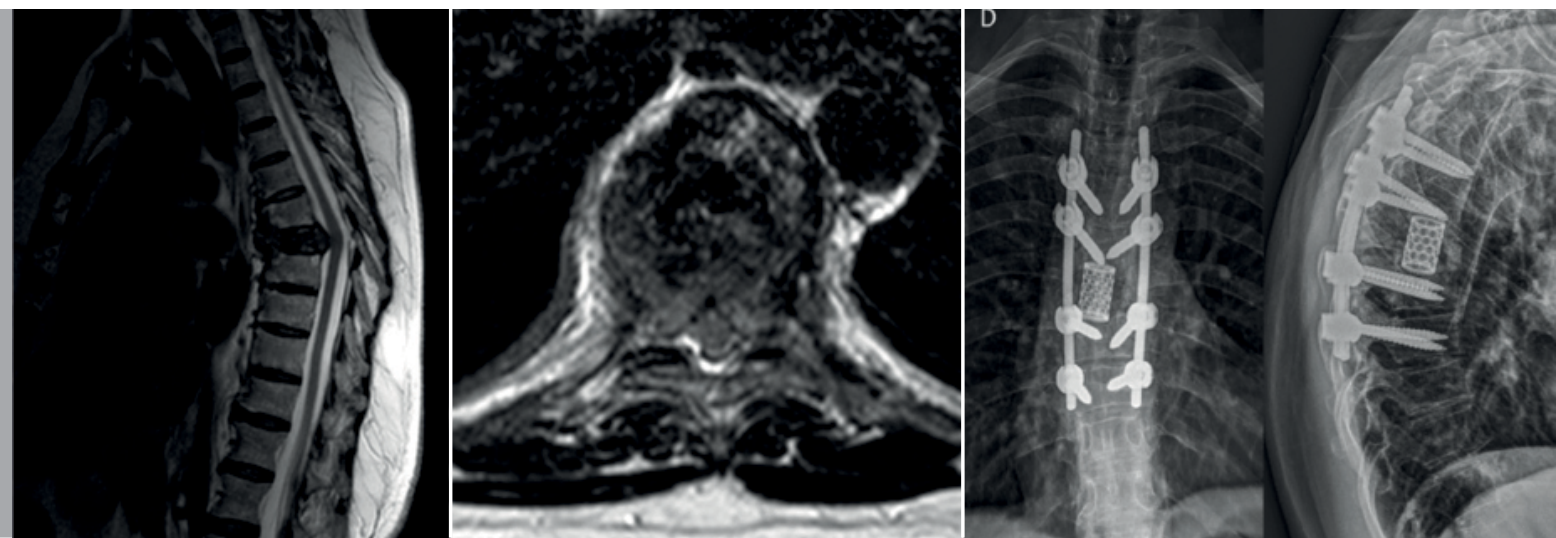

Figure 2. Sagittal and axial cuts of T2-weighted preoperative magnetic resonance showing metastatic assailment of the T7 vertebral body and spinal compression. Postoperative radiographies of decompression and posterior fixation with pedicular screws associated with corpectomy and replacement with intersomatic device filled with bone cement.

This is in accordance with the literature, which shows that breast cancer is relatively rare before the age of 35 , progressively growing in incidence, especially after the age of $60 .{ }^{1}$ In $13.6 \%$ of the patients, diagnosis of spinal metastasis preceded the diagnosis of primary tumor, since it can detect failure in screening and in the early diagnosis or even high tumor aggressiveness. Frequently, the presence of pain is not appreciated, and the correct diagnosis is postponed until more evidences of spinal or root dysfunction manifest. ${ }^{10}$

Based on the available medical literature, the mean rate of neurological improvement is $63.8 \%$ (53\% to $100 \%$ ), and of decline is $4.1 \%$ (0\% to $8 \%) .{ }^{4}$ In this study, $22.7 \%$ showed improvement in Frankel's classification, and only $2.2 \%$ neurologically worsened. According to Molina, ${ }^{7}$ outcomes are not clinically significant among the different surgical approaches employed, and the reported results of pain relief were almost identical for posterior decompression and decompression with fixation. The contributions of concomitant and adjuvant treatment administered in the perioperative context should be considered. ${ }^{8}$

The choice of the most appropriate surgical approach for an individual case depends on several factors, including tumor pathology, location, and patient's overall status. ${ }^{11}$ The best technique should provide adequate exposure to safely remove the injury. ${ }^{7}$ Decompression by laminectomy is usually considered with metastatic involvement of the epidural space and blade, but it is limited because it does not allow the decompression of the ventral epidural spinal cord. ${ }^{7}$ The addition of instrumentation to stabilize a laminectomy can protect against instability due to tumor involvement in the facet joints, pedicles or anterior vertebral body. ${ }^{7}$ Approaches with corpectomy and replacement with intersomatic device provide the extra benefit of ventrally decompressing the spinal cord or dural sac and increasing the space between the injury and the spinal cord. ${ }^{7}$

A review of multiple series of surgical treatments for metastatic disease in the spine, cited by Shehadi ${ }^{8}$, shows that complication rates range from $10 \%$ to $52 \%$. In this study, $18.1 \%$ of the patients presented postoperative complications, which shows the procedures employed had lower morbidity rates. Of the individuals studied, $16 \%$ were reapproached due to tumor recurrence. Data available in the literature are congruent with the clinical notion that circumferential decompression results in more complete tumor resections, and thus decreases recurrence. ${ }^{7}$ In this study, $75 \%$ of the patients who presented complications were submitted to decompression, fixation with pedicular screws, corpectomy and replacement with intersomatic device. Patients submitted to kyphoplasty did not present complications, which may support the idea that complication rates increase with major surgeries, since kyphoplasty is a minor procedure, fastly executed and does not require long periods of hospitalization in the postoperative. ${ }^{12}$

The thoracic spine was the most frequent site of secondary assailment in this study (86.3\%), followed by lumbar (25\%) and cervical (13.6\%) levels. This corresponds to the international literature, in which metastasis to the thoracic spine corresponds to $70 \%$, to the lumbar spine, $20 \%$, and to the cervical spine, $10 \% .^{13,14}$ On the other hand, the posterior portion of the vertebrae was more affected than the anterior portion in this study, different from the established in other studies, in which most metastases occur in the anterior region, corresponding to the vertebral body. ${ }^{6}$ Algra and collaborators $^{15}$ showed, with tomography analysis, the vertebral body was the portion most frequently affected by metastases, and the destruction of a pedicle was unidentified in the lack of body involvement. The opposite was true when assessing simple exams, in which the most common finding was the assailment of the pedicles. ${ }^{15}$ Therefore, we assume that depending on the imaging exam to be evaluated, the initial findings may diverge. Besides, this study included only individuals submitted to the posterior surgical approach.

\section{CONCLUSIONS}

The clinical and radiological presentation of patients with breast metastasis lesions in the spine is variable, similar to that described in the literature, except that the posterior portion of the vertebrae was more affected than the anterior portion in the sample of this study. Although surgical treatment by posterior approach does not aim to cure the underlying disease, it may have favorable results, improving the quality of life and neurological prognosis, with higher complication rates in major procedures.

AUTHORS' CONTRIBUTIONS: Each author contributed individually and significantly to the development of this article: MDSP: literature review, data collection and analysis, writing of the article. BPFP: literature review, data collection, writing of the article. FPA: literature review, data collection, writing of the article. CFPSH: development of the research project, data analysis, review of the article to be published. 


\section{REFERENCES}

1. Instituto Nacional de Câncer (Brasil). Câncer de Mama [Internet]. Brasília: Inca; 2017 [cited 2017 Apr 10]. Available from: https://www.inca.gov.br/ tipos-de-cancer/cancer-de-mama

2. Walcott BP, Cvetanovich GL, Barnard ZR, Nahed BV, Kahle KT, Curry WT. Surgical treatment and outcomes of metastatic breast cancer to the spine. J Clin Neurosci. 2011;18(10):1336-9.

3. Conte PF, Bengala C, Guarneri V. Controversies of chemotherapy for the treatment of metastatic breast cancer. Eur J Cancer Suppl. 2007;5(1):11-6.

4. Sciubba DM, Goodwin CR, Yurter A, Ju D, Gokaslan ZL, Fisher C, et al A Systematic Review of Clinical Outcomes and Prognostic Factors for Patients Undergoing Surgery for Spinal Metastases Secondary to Breast Cancer. Global Spine J. 2016;6(5):482-96.

5. Oliveira AV Jr, Bortoletto A, Rodrigues LCL. Avaliação do tratamento cirúrgico nos pacientes com metástase vertebral secundária ao carcinoma de mama. Coluna/Columna. 2012;11(3):226-9.

6. Wu AS, Fourney DR. Evolution of treatment for metastatic spine disease. Neurosurg Clin N Am. 2004;15(4):401-11.

7. Molina C, Goodwin CR, Abu-Bonsrah N, Elder BD, De la Garza Ramos R, Sciubba DM. Posterior approaches for symptomatic metastatic spinal cord compression. Neurosurg Focus. 2016;41(2):E11.
8. Shehadi JA, Sciubba DM, Suk I, Suki D, Maldaun MV, McCutcheon IE, et al. Surgical treatment strategies and outcome in patients with breast cancer metastatic to the spine: a review of 87 patients. Eur Spine J. 2007;16(8):1179-92.

9. van Middendorp JJ, Goss B, Urquhart S, Atresh S, Williams RP, Schuetz M. Diagnosis and Prognosis of Traumatic Spinal Cord Injury. Global Spine J. 2011;1(1):1-8

10. Perrin RG, Laxton AW. Metastatic spine disease: epidemiology, pathophysiology, and evaluation of patients. Neurosurg Clin N Am. 2004;15(4):365-73.

11. Tokuhashi $Y$, Matsuzaki H, Oda H, Oshima M, Ryu J. A Revised Scoring System for Preoperative Evaluation of Metastatic Spine Tumor Prognosis. Spine (Phila Pa 1976). 2005;30(19):2186-91.

12. Costa J, Andrade A, Martins J, Berhanu N, Rodrigues J. Tratamento das metástases vertebrais. Rev Port Ortop Traum. 2014;22(4):350-9.

13. Klimo P Jr, Schmidt MH. Surgical Management of Spinal Metastases. Oncologist. 2004;9(2):188-96.

14. Korukian M, Jesus-Garcia R, Ishihara H, Ponte FM, Viola DCM. Tratamento das metástases do tumor de mama na coluna vertebral. Rev Bras Ortop. 2006;41(4):116-21.

15. Algra PR, Heimans JJ, Valk J, Nauta JJ, Lachniet M, Van Kooten B. Do Metastases in Vertebrae Begin in the Body or the Pedicles? Imaging Study in 45 Patients. AJR Am J Roentgenol. 1992;158(6):1275-9. 